\title{
Repercussões da radioterapia na região orofacial e seu tratamento*
}

\author{
Impact of radiotherapy on the orofacial region and management of related conditions
}

Ana Emília Holanda Rolim ${ }^{1}$, Lino João da Costa², Luciana Maria Pedreira Ramalho ${ }^{3}$

\begin{abstract}
Resumo A radioterapia em região de cabeça e pescoço provoca inúmeras sequelas ao paciente irradiado, afetando o sistema estomatognático e com repercussões sistêmicas importantes. As sequelas da radiação ionizante podem ser extensas e, algumas vezes, permanentes, em especial nas glândulas salivares e no tecido ósseo. É relevante que o cirurgião dentista tenha conhecimento das reações adversas e das formas adequadas de prevenção e tratamento para amenizar o desconforto e melhorar a condição de vida do paciente irradiado. Portanto, a conscientização e motivação deste paciente, com a promoção de saúde oral através da adequação do meio bucal e orientações sobre ações preventivas, são essenciais para se obter o melhor prognóstico.
\end{abstract}

Unitermos: Tumores de cabeça e pescoço; Radioterapia; Efeitos agudos; Efeitos tardios.

Abstract Head and neck radiotherapy causes countless sequelae in irradiated patients, affecting the stomatognathic system, with significant systemic implications. Sequelae of exposure to ionizing radiation may be extensive and sometimes permanent, particularly in the salivary glands and bone tissue. It is of utmost importance that the surgeon dentist be aware of adverse reactions and appropriate forms of treatment to alleviate discomfort and improve the quality of life of the irradiated patient. Therefore, awareness and motivation of the patient, with promotion of oral health through the adaptation of the oral environment and guidance on preventive measures are essential to get a better prognosis.

Keywords: Head and neck tumors; Radiotherapy; Acute effects; Late effects.

Rolim AEH, Costa $\sqcup$, Ramalho LMP. Repercussões da radioterapia na região orofacial e seu tratamento. Radiol Bras. 2011 Nov/ Dez;44(6):388-395.

\section{INTRODUÇÃO}

A radioterapia é uma modalidade de tratamento que consiste na utilização de energia ionizante eletromagnética ou corpuscular, capaz de interagir com os tecidos no tratamento de neoplasias malignas. Os elétrons são deslocados nos tecidos, ionizam o meio e provocam efeitos químicos e biológicos, como danos no DNA, que impedem a replicação de células neoplásicas $^{(1)}$. Todavia, o tratamento ionizante não é seletivo e atua também em células

* Trabalho realizado na Universidade Federal da Bahia (UFBA), Salvador, BA, Brasil.

1. Cirurgiã dentista, Doutoranda em Processos Interativos de Órgãos e Sistemas do Programa de Pós-graduação da Universidade Federal da Bahia (UFBA), Salvador, BA, Brasil.

2. Doutor em Diagnóstico Bucal, Professor Titular do Depar tamento de Clínica e Odontologia Social da Universidade Federal da Paraíba (UFPB), João Pessoa, PB, Brasil.

3. Doutora em Odontologia, Professora Adjunta do Departamento de Diagnóstico e Terapêutica da Universidade Federal da Bahia (UFBA), Salvador, BA, Brasil.

Endereço para correspondência: Dra. Ana Emília Holanda Rolim. Rua Poetisa Cora Coralina, 229, Edifício Solar do Vale, ap. 204, Santa Teresa. Salvador, BA, Brasil, 40265-070. E-mail: anaemilia.rolim@gmail.com

Recebido para publicação em 11/5/2011. Aceito, após revisão, em 22/9/2011. saudáveis, o que o torna tóxico para o organismo $^{(2)}$.

A dose de radiação é medida em unidade gray (Gy), sendo que, geralmente, os pacientes com carcinomas de cabeça e pescoço recebem, como dose curativa, entre 50 e 70 Gy $(1 \mathrm{~Gy}=1 \mathrm{~J} / \mathrm{kg}=100 \mathrm{rads})$. Esta dose geralmente é aplicada de forma fracionada, por um período de cinco a sete semanas, uma vez ao dia, cinco dias na semana e com uma dose diária no tumor em torno de $2 \mathrm{~Gy}^{(\mathbf{3 , 4})}$. Em doses baixas de 10 Gy já há o aparecimento de efeitos colaterais (síndrome cutânea de radiação, mucosite e alterações glandulares) ${ }^{(\mathbf{4})}$.

As elevadas doses de radiação podem causar hipóxia, redução de suprimento sanguíneo, necrose e suscetibilidade para infecção. A pele, no campo de irradiação, poderá apresentar como sequelas: eritema, descamação, formação de bolhas, necrose, e também dor e ardência. Na mucosa bucal, além das mudanças histofisiológicas, podem ocorrer alterações estruturais e funcionais dos tecidos de suporte ${ }^{(\mathbf{5})}$. As complicações sistêmicas mais frequentes ocor- rem em $65 \%$ a $100 \%$ dos casos e caracterizam-se pela presença de mal-estar, náuseas e vômitos ocasionais, anorexia e fa$\operatorname{diga}^{(2)}$.

O objetivo desta revisão atualizada da literatura é esclarecer a ação da radioterapia em lesões neoplásicas orais, suas indicações, descrever os mecanismos biológicos, os efeitos adversos, os protocolos de tratamento atuais, e promover uma melhor conduta clínica do cirurgião dentista, diante destes pacientes irradiados.

\section{MATERIAIS E MÉTODOS}

Realizou-se uma revisão atualizada da literatura de artigos científicos que abordavam o tema nas seguintes bases de dados: Bireme, Medline, Cancerlit, Scirus, Portal Capes, SciELO, Medscape, PubMed. Os seguintes descritores foram empregados na busca das publicações: oral mucositis, radiotherapy, stomatitis, neoplasm, xerostomia, osteoradionecrosis, candidiasis, cancer, dentistry, laser therapy, LLLT, head and neak tumors, sequelae. Os mesmos 
descritores em português também foram utilizados.

No período de 1985 a 2011 foram recuperados 100 artigos científicos para análise, procedendo-se então a leitura exploratória e análise crítica de todo o material. Dos artigos mencionados, 59 não foram considerados, por apresentarem limitações nos métodos ou por serem artigos publicados antes de 2000, sem grande número de citações. Assim, foram selecionados para análise 41 estudos, incluindo-se livros, revisões, estudos de casos, pesquisas clínicas multicêntricas e publicações do Instituto Nacional de Câncer e do Instituto do Texas de Pesquisa e Prevenção do Câncer. A maioria destas referências correspondeu ao período de 2000 a 2011, nos idiomas português e inglês, publicadas em periódicos nacionais e internacionais. Como exceção foram incluídos cinco artigos, publicados em inglês em revistas com alto fator de impacto, anteriores a 2000, que apresentaram um número de citações superior a três. Sete artigos foram em português, publicados em revistas nacionais, além de dois livros de referência.

Os dados coletados foram organizados em planilha do Microsoft Office Excel, versão 2003. Esta planilha continha: a referência; o ano de publicação; o número de citações; o tipo de estudo; as principais intervenções para a prevenção e o tratamento das sequelas da radioterapia segundo os achados da revisão de literatura; a apresentação das intervenções mais recomendadas pelos autores.

\section{REVISÃO DE LITERATURA}

A radioterapia promove alterações químicas, físicas e biológicas ao nível celular, por ação direta e obliteração da microcirculação local. O efeito positivo desta terapia depende da capacidade de reparo, da repopulação, redistribuição e reoxigenação das células, tecidos e órgãos. Dessa forma, os efeitos colaterais variam de acordo com a capacidade biológica de resposta de cada indivíduo e dependem da área irradiada, quantidade de radiação administrada, tipo e radiossensibilidade do tecido saudável envolvido pela radiação, do fracionamento da dose, idade e condições sistêmicas do paciente. Além disso, outros fatores mo- dificadores devem ser considerados, como o alcoolismo e o tabagismo e, principalmente, as situações que podem comprometer a integridade da mucosa bucal, como uma prótese mal adaptada, cárie e doença periodontal pré-existentes, hábitos de higiene deficiente, estado das restaurações e dos tratamentos endodônticos realizados, conscientização e colaboração do paciente durante o tratamento radioterápico ${ }^{(2,6)}$.

Estes efeitos deletérios podem ocorrer de forma imediata durante o tratamento e/ou meses a anos após o término. Os efeitos e sintomas agudos mais frequentes da radioterapia de cabeça e pescoço são: disfagia, odinofagia, mucosite, sangramento, presença de infecções oportunistas como candidíase, xerostomia, disgeusia, periodontopatias, emagrecimento, rouquidão, alterações de pele ${ }^{(7,8)}$.

Como efeitos tardios ao tratamento com radiação ionizante se destacam: cáries de radiação, fibrose de tecido subcutâneo, trismo, ulcerações de pele e/ou mucosa, infecções, necrose de cartilagens, fístulas, alterações auditivas e oftalmológicas, alterações hormonais (hipotireoidismo), edema da face e do pescoço, dor, queda de cabelo, dormência e/ou formigamento dos membros superiores, mielite cervical, osteorradionecrose ${ }^{(6,9)}$.

\section{PREVENÇÃO E TRATAMENTO DAS SEQUELAS DA RADIOTERAPIA}

A necessidade de manutenção da saúde oral do paciente oncológico submetido a radioterapia tem por objetivo proporcionar uma melhor qualidade de vida ${ }^{(\mathbf{1 0})}$. O periodonto deve ser mantido em condições saudáveis por meio de procedimentos executados rotineiramente, antes e durante a irradiação. A orientação das técnicas de higiene oral, a motivação e a capacidade de cooperação do paciente são essenciais para alcançar o melhor prognóstico ${ }^{(11-13)}$.

Um método para avaliação da necessidade de extrações dentárias, em pacientes oncológicos, prévio ao tratamento radioterápico, foi proposto por Bruins et al. ${ }^{(14)}$. Dentre os critérios de avaliação estão: condição dental (periodontal, endodôntica, dentes impactados), localização dental, importância do dente na cavidade oral, dose de radiação e o grau da doença periodontal ${ }^{(\mathbf{1 5})}$.
Os pacientes com histórico prévio de doença periodontal com grande perda óssea podem ter sérias complicações nas exodontias, como a osteorradionecrose. A extração dentária prévia ao tratamento radioterápico estará indicada nos casos em que houver bolsas periodontais maiores do que $6 \mathrm{~mm}$ ou maiores do que $4 \mathrm{~mm}$ com mobilidade grau I ${ }^{(\mathbf{1 1})}$.

A redução da perfusão sanguínea dos tecidos irradiados leva a uma progressiva redução da oxigenação tecidual, bem como dos mecanismos de resposta imunológica do hospedeiro e da quantidade e qualidade da saliva ${ }^{(8)}$. A saliva perde seu potencial antimicrobiano, de tamponamento e de remineralização. Com isso, alguns microrganismos são favorecidos a se desenvolverem em meio oral, entre estes, os microrganismos anaeróbios obrigatórios, da espécie Porphyromonas gingivalis, presentes em pacientes irradiados após seis meses do tratamento. Estas bactérias participam no desenvolvimento das periodontites laterais, infecções endodônticas, abscessos agudos, anginas e celulite facial. As $P$. gingivalis induzem a liberação citocinas, que podem contribuir para que a resposta local e sistêmica do hospedeiro seja ineficaz, perpetuando um quadro inflamatório.

O acúmulo da placa bacteriana aumenta a gravidade das infecções das mucosas, além de predispor à gengivite, e se o paciente apresentar plaquetopenia podem ocorrer sangramentos espontâneos. Além disso, os episódios sépticos em pacientes neutropênicos estão relacionados com a microbiota oral $^{(\mathbf{1 6})}$. Com isso, o controle de infecções na cavidade oral permite dar prosseguimento ao próprio tratamento com a radioterapia, visto que a presença de infecções não controladas torna-se um fator limitante ao sucesso dessa terapia, e o uso de fármacos antimicrobianos é problemático nesses pacientes. Dessa forma, é imprescindível orientar a maneira adequada de higienização oral desses pacientes.

Ainda na adequação do meio bucal, as restaurações não devem ser de amálgama, pelo fato deste material emitir radiação secundária e pela possibilidade do paciente desenvolver uma reação liquenoide, pelo contato deste material na mucosa oral ${ }^{(\mathbf{1 6})}$. Como opção, pode-se utilizar protetores de polivinilsiloxano, com $5 \mathrm{~mm}$ de espessura, 
para proteger os dentes com restaurações metálicas, e protetores linguais para minimizar os efeitos deletérios da radiação ${ }^{(\mathbf{1 7})}$. Nestes pacientes, portanto, o tratamento deve ser planejado de modo multidisciplinar e personalizado, conforme a necessidade do paciente. A seguir, expõem-se alguns exemplos de condutas terapêuticas encontradas na literatura.

\section{MUCOSITE}

É caracterizada por descamação da mucosa, eritema, pseudomembrana e ulceração. Surge, normalmente, após sete dias do início da terapia, a partir de uma dose entre 10 e $30 \mathrm{~Gy}$, podendo desaparecer em duas a quatro semanas após o término do tratamento $^{(\mathbf{1 8})}$. Os sintomas dor e queimação ocorrem, principalmente, na ingestão de alimentos condimentados e de texturas ásperas, o que dificulta a higiene oral e a deglutição do alimento. $\mathrm{O}$ aumento da incidência de mucosite tem sido relacionado ao crescente consumo de álcool e tabaco, sendo agravado por fatores traumáticos locais como, por exemplo, próteses mal

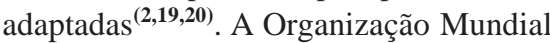
da Saúde definiu escores para graduação da mucosite, em que o grau 0 representa ausência da mucosite, grau I representa eritema, grau II apresenta eritema, edema e úlcera dolorosa e o paciente ainda consegue se alimentar de sólidos, grau III representa um quadro grave com ulcerações orais e o paciente consegue se alimentar apenas de líquidos, e grau IV representa o paciente que já não consegue se alimentar pela boca, necessitando de suporte nutritivo enteral ou parenteral ${ }^{(\mathbf{1 , 2 0})}$.

\section{Tratamento}

A laserterapia é uma alternativa recomendada para o tratamento da mucosite, visto que a luz laser estimula a atividade celular, favorece a liberação de fatores de crescimento por macrófagos e a proliferação de queratinócitos, aumenta a população e a degranulação de mastócitos e promove a angiogênese. Esses efeitos aceleram o processo de cicatrização de feridas devido, em parte, à redução na duração da inflamação aguda. Além disso, a aplicação diária do laser reduz a intensidade, a gravidade e a duração da mucosite, além de diminuir a dor e a administração de morfina $^{\text {(21-24) }}$. Antes desta terapia deve-se avaliar cuidadosamente o paciente e os parâmetros da laserterapia e, além disso, evitar aplicações em áreas tumorais. Para minimizar os efeitos da radiação, no tratamento da mucosite e da xerostomia, tem-se sugerido a aplicação do laser de baixa potência, com comprimento de $685 \mathrm{~nm}$, de maneira contínua, potência de $35 \mathrm{~mW}$ e 1 a 4 J/ponto, com aplicação nos seguintes pontos: 3 pontos em cada parótida; 1 ponto submandibular direito e outro esquerdo; 2 pontos na mucosa jugal, na direita e na esquerda; 1 ponto em cada lado do assoalho da boca; 2 pontos na língua; 1 ponto em cada pilar da orofaringe; e 1 ponto na úvula ${ }^{(23)}$. A laserterapia, com pontos semelhantes de aplicação, com os parâmetros de $830 \mathrm{~nm}, 15$ $\mathrm{mW}, 12 \mathrm{~J} / \mathrm{cm}^{2}$ e $2,4 \mathrm{~J}$, aplicada diariamente desde o primeiro dia até o final da radioterapia antes de cada sessão durante cinco dias consecutivos, mostrou resultados mais satisfatórios quando comparada com a administração de hidróxido de alumínio 310 $\mathrm{mg} / 5 \mathrm{ml}$, quatro vezes ao dia, também por toda a duração da radioterapia ${ }^{(25)}$. Todavia, em outro estudo com aplicação do laser com parâmetros de $660 \mathrm{~nm}, 10 \mathrm{~mW}, 2,5 \mathrm{~J} / \mathrm{cm}^{2}$ e $0,1 \mathrm{~J}$, em 75 pacientes oncológicos, não houve resultados satisfatórios na redução da mucosite graus III e IV ${ }^{(26)}$.

A reparação ou eliminação de todas as fontes potenciais de irritação, tais como cúspides agudas e fraturadas, grampos quebrados, prótese mal adaptada, ou bandas ortodônticas são importantes antes da radioterapia $^{(4)}$.

É importante orientar o paciente para que evite ingerir alimentos duros, quentes, ácidos ou condimentados e que se mantenha sempre hidratado. Para os lábios recomenda-se o uso de manteiga de cacau ${ }^{(5)}$.

Em alguns casos é necessário prescrever anestésicos tópicos (acetonido de triancinolona; benzocaína tópica ou solução; cloridrato de lidocaína suspensão a $2 \%$; cloridrato de lidocaína e prilocaína tópicas), ou nos casos de sintomas dolorosos mais severos, analgésicos sistêmicos ${ }^{(27)}$.

O uso de corticoides associados com antibiótico pode ser necessário em infecções secundárias, oportunistas, como, por exemplo: prednisona 40 a $80 \mathrm{mg}$, via oral, diariamente por uma semana; dexameta- sona $5 \mathrm{ml}$, de $8 / 8$ horas, durante sete dias, alternada a bochechos com eritromicina $250 \mathrm{mg} / 5 \mathrm{ml}$, de 8/8 horas, durante sete dias ${ }^{(27)}$. Nos casos de mucosite associada com candidíase, recomenda-se o uso de antifúngico: suspensão de nistatina, bochechar e deglutir metade, quatro vezes ao dia; ou comprimidos de clotrimazol, $10 \mathrm{mg}$, cinco vezes ao dia; e se a Candida estiver sob a prótese ou nos ângulos da boca, devese aplicar nistatina creme, 100.000 unidades/g, em tubos de 15 ou 30 g, três vezes ao dia. Em crianças é recomendado o uso da suspensão de nistatina, 1/2 a 3/4 de colher de sopa para cada bandeja de cubos de gelo, congelar e usar como picolé ou pedras de gelo $^{(27)}$

O uso de solução de clorexidina $0,12 \%$ ou $0,2 \%$, duas vezes ao dia, ou solução de povidine iodado100 ml (1:8 de diluição) pode ser instituído como tratamento. Uma solução constituída por cloridrato de difenidramina (solução aquosa a $0,25 \%$ ), cloridrato de lidocaína a $2 \%$, nistatina $(100.000 \mathrm{u} / \mathrm{ml})$ e um composto antiácido (200 mg de hidróxido de magnésio, 200 mg de hidróxido de alumínio e 20 mg de dimeticona) numa proporção de $30 \mathrm{ml}$ de cada, quatro a seis vezes ao dia, ajuda a aliviar os sintomas da mucosite ${ }^{(2,27)}$.

Água bicarbonatada (uma colher de chá de bicarbonato de sódio em duas xícaras de água) a cada duas horas ou água salina (uma colher de chá de sal para 1/4 de xícara de água) ajuda a reduzir a irritação das mucosas, aumenta a umidade na boca e remove secreções e detritos, sendo recomendada também para o tratamento de gengivites leucêmicas ${ }^{(5)}$. Essa solução pode ser associada a hidrocloreto de benzidamida para a redução da dor.

$\mathrm{O}$ uso de agentes citoprotetores é relatado na literatura. Por exemplo, a aminofostina, 15 a 30 minutos antes de cada radiação, por 6 a 7,5 semanas, estimula a proliferação de células basais e a reparação tecidual $^{(28)}$. Também resultados satisfatórios são evidentes com o uso de nitrato de prata $^{(\mathbf{2 8})}$, esteroides, vitamina E e suplementação oral com glutamina ${ }^{(29-32)}$.

\section{HIPOGEUSIA E DISGEUSIA}

A irradiação pode afetar as papilas gustativas quando a língua está localizada no 
campo de irradiação, provocando a perda da sensação gustativa ${ }^{(4)}$. Essas alterações iniciam-se por volta da primeira ou da segunda semana de irradiação, podendo haver progressão até o fim do tratamento. Essas mesmas alterações do paladar são afetadas pela diminuição do fluxo salivar e na mucosite ${ }^{(33)}$.

A hipogeusia é definida como a diminuição ou perda substancial dos quatro paladares, resultante do comprometimento dos botões gustativos e também reflexo da estomatite e da xerostomia. Para a maioria dos pacientes, os sentidos retornam em quatro meses, porém em alguns casos as sequelas são permanentes.

A disgeusia ocorre antes dos sintomas de mucosite ${ }^{(4)}$. As papilas gustativas sofrem atrofia com doses em torno de $10 \mathrm{~Gy}$. Com isso, a percepção dos sabores ácido e amargo é mais comumente afetada no começo da irradiação, e posteriormente, há alteração gustativa para os sabores doce e salgado. Essas alterações da sensação são transitórias e reversíveis, havendo retorno da percepção por volta de dois a quatro meses após a radioterapia ${ }^{(\mathbf{1 , 3 , 4})}$.

\section{Tratamento}

Em razão de todas estas alterações, o paciente apresenta fraqueza, mal-estar, desidratação, perda de apetite, repercutindo negativamente em seu quadro geral. Nestes casos, em que a saúde oral e sistêmica está comprometida, o paciente deve monitorar frequentemente seu peso e fazer acompanhamento com um nutricionista ${ }^{(5)}$.

A suplementação com zinco e cobre, preventivamente e ao longo de toda a radioterapia, até um período de tempo após o término do tratamento, pode reduzir a disgeusia $^{(31,34)}$.

\section{INFECÇÕES OPORTUNISTAS}

A mucosite pode ser agravada por infecções fúngicas (Candida albicans), viróticas e bacterianas (bacilos Gram positivos e Gram negativos). Alguns fatores devem ser avaliados em pacientes com infecções orais: disfunções endócrinas, lesões em mucosas, higiene oral deficiente, tratamento prolongado com antibióticos e corticoides. Os pacientes irradiados são imunossuprimidos, ou seja, sua função imunológica está debilitada para o combate de microrganismos da própria microbiota bucal e outros oportunistas. Outro fator predisponente do paciente irradiado é a redução do fluxo salivar e da qualidade da saliva $^{(18)}$.

A origem da infecção local, na boca, ou sistêmica muitas vezes é decorrente de uma infecção periodontal ou endodôntica preexistente.

Em pacientes neutropênicos, a candidíase bucal pode causar septicemia fúngica, sendo $60 \%$ dos casos de óbitos associados a infecções preexistentes. As lesões ulcerativas da mucosa ou o comprometimento do trato gastrintestinal podem ser fatores relacionados à infecção fúngica sistêmica ${ }^{(16)}$.

As lesões virais decorrentes de infecções herpéticas também são comuns em pacientes oncológicos em tratamento radioterápico e podem comprometer qualquer área da mucosa bucal, não apenas a mucosa queratinizada $^{(\mathbf{1 6})}$.

\section{Tratamento}

As infecções fúngicas devem ser tratadas com peróxido salino de hidrogênio ou o uso de antifúngicos tópicos como a nistatina, preferencialmente em pó ou em suspensão sem açúcar na sua composição, clotrimazol, cetoconazol e clorexidina. Para as infecções mais graves, é necessária a prescrição de antifúngicos sistêmicos como o cetoconazol $200 \mathrm{mg}$ uma vez ao dia, até uma semana após o desaparecimento dos sinais e sintomas, ou o fluconazol, $100 \mathrm{mg}$ por dia, de 7 a 14 dias, ou ainda a anfotericina $\mathrm{B}^{(27)}$.

A clorexidina $0,12 \%$ pode também ser prescrita. Recomenda-se enxaguatório, no mínimo, 30 minutos antes ou após o uso de qualquer agente antifúngico tópico e da escovação. Seu uso deve ser duas vezes ao dia, por no máximo sete dias, pois o uso prolongado altera a flora oral, retarda a cicatrização, e o álcool pode desidratar a mucosa oral. Além disso, a clorexidina pode causar manchas nos dentes e restaurações, reduzir a eficácia do creme dental e da nistatina, favorecer o crescimento bacteriano (Pseudomonas), apresentar gosto desagradável e afetar o paladar ${ }^{(\mathbf{2 , 5})}$.

Nas infecções bacterianas recomendase a prescrição de antibióticos tópicos ou sistêmicos. O uso de peróxido de hidrogênio, em forma de soluções diluídas (1:4) por períodos curtos de um a dois dias, é recomendado em infecções bacterianas periodontais. Os efeitos adversos de seu uso prolongado são: atraso na cicatrização de feridas, desmineralização do esmalte, indução de emese, boca seca, sede e desconforto, favorecimento de crescimento de fungos, gosto desagradável ${ }^{(\mathbf{5})}$.

Nas infecções virais, especialmente pelo herpes, em adultos imunossuprimidos, recomenda-se o uso de aciclovir $400 \mathrm{mg}$, dois comprimidos de $200 \mathrm{mg}$, de 6/6 horas, durante cinco dias. Em crianças, a dose de aciclovir é de $30 \mathrm{mg} / \mathrm{kg} / \mathrm{dia}$, de 8/8 horas, ou opção por uso tópico de 4/4 horas, durante sete dias ${ }^{(\mathbf{1 6})}$. O laser de baixa potência é também eficaz nos casos de herpes na fase de cicatrização das lesões ${ }^{(\mathbf{1 2})}$.

\section{XEROSTOMIA}

A radiação, quando aplicada em doses entre 40 e 65 Gy, provoca uma reação inflamatória degenerativa, especialmente das células serosas acinares das glândulas salivares. Além disso, a ansiedade e depressão, muitas vezes presentes nesses pacientes, favorecem o aparecimento da xerosto$\operatorname{mia}^{(5)}$.

O fluxo salivar nos pacientes irradiados na região de cabeça e pescoço pode diminuir em até $90 \%$, em nível inferior a $0,3 \mathrm{ml} /$ min, tornando a saliva viscosa, com mais conteúdo orgânico, com diminuição da transparência ou com coloração amarelada. Nos casos mais acentuados, os pacientes apresentam a mucosa sem qualquer umidificação, dificultando a mastigação e a preparação do bolo alimentar, e consequentemente, a deglutição e até mesmo a fala. Há alteração na gustação, que provoca disfagia, alteração nutricional com perda do apetite e do peso, e dessa forma, a qualidade de vida do paciente fica comprometida $^{(3)}$

A perda da função salivar causa numerosas sequelas adversas, incluindo: disfunção esofágica (esofagite crônica); maior frequência de intolerância aos medicamentos orais e produtos de higiene bucal; aumento da incidência de infecção local/regional (glossite, candidíase, cárie dentária, halitose, sialoadenite bacteriana); alteração 
do $\mathrm{pH}$ e menor capacidade tampão; redução da capacidade remineralizante, levando a sensibilidade dentária e suscetibilidade maior à cárie dentária; diminuição da resistência da estrutura dental devido a abrasão, atrito e erosão (corrosão); aumento da suscetibilidade a lesões da mucosa; incapacidade de usar próteses dentárias ${ }^{(\mathbf{5})}$.

A xerostomia permanente é um dos efeitos tardios mais prevalentes ${ }^{(\mathbf{1})}$. É necessário avaliar o fluxo salivar, por meio de sialometria em repouso e estimulada desses pacientes (Tabela 1).

Tabela 1 Sialometria.

\begin{tabular}{ccc}
\hline & $\begin{array}{c}\text { Salivação } \\
\text { em repouso } \\
(\mathrm{ml} / \mathrm{min})\end{array}$ & $\begin{array}{c}\text { Salivação } \\
\text { estimulada } \\
(\mathrm{ml} / \mathrm{min})\end{array}$ \\
\hline Hipossalivação & $<0,1$ & $<0,7$ \\
Baixo fluxo & $0,1-0,25$ & $0,7-1,0$ \\
Normal & $0,25-0,35$ & $1,0-3,0$ \\
\hline
\end{tabular}

\section{Tratamento}

São recomendados, para estes pacientes com xerostomia, a correta ingestão de água (8 a 12 copos/dia), bebidas sem açúcar, chicletes e balas sem de açúcar, alimentos ricos em ácido ascórbico, ácido málico ou ácido cítrico, evitar café, refrigerantes, chás e alimentos muito salgados, não fumar ou beber bebidas alcoólicas ${ }^{(\mathbf{3 1}, \mathbf{3 2}, \mathbf{3 4})}$.

Os testes de fluxo salivar devem ocorrer não apenas no exame inicial antes da radioterapia, mas serem periódicos para avaliar os danos funcionais às glândulas salivares. Para os pacientes irradiados, o controle dos microrganismos orais é necessário, e para isso a clorexidina gel 2\%, 5 minutos/dia, durante 14 dias, promove resultados satisfatórios. Porém, em alguns casos é necessário repetir o uso a cada três ou quatro meses, até o fluxo salivar voltar ao normal ${ }^{(5,35)}$.

O uso de saliva artificial ou de umidificadores da boca é alternativa para os casos de hipossalivação. Estes mantêm o pH da boca entre 6,0 e 7,0 e nas suas composições podem conter constituintes importantes para a remineralização dentária: carboximetilcelulose, xilitol, flúor, aminoácidos, enzimas, glicerol, íons cálcio e fosfato ${ }^{(5)}$.

O uso sistêmico de sialogogos é uma opção de tratamento nos casos mais graves. Pode-se prescrever a pilocarpina, a cevime- lina e a urecolina. A pilocarpina, $5 \mathrm{mg}$ três a quatro vezes ao dia, via oral, pode-se iniciar um dia antes do tratamento com radioterapia, não excedendo $30 \mathrm{mg} /$ dia. Evitar o uso tópico na forma de gel ou spray, pois os efeitos são inferiores à administração sistêmica $^{(5,13)}$. A urecolina é análoga da acetilcolina, pode ser prescrita dose de 25 $\mathrm{mg}$, três vezes ao dia, durante duas a três semanas, mas deve-se suspender o seu uso por uma semana se se fizer uso de outro sialogogo. A anetoltritiona e a cevimelina, $30 \mathrm{mg}$ de 4/4 horas, também são estimulantes salivares de uso sistêmico ${ }^{(\mathbf{1 3})}$.

A solução salina $0,9 \%(0,9 \mathrm{mg}$ de $\mathrm{NaCl}$ em 100 ml de água) ou a solução de bicarbonato, em bochechos de 12-30 segundos, a cada 6 horas ou a cada 15-30 minutos, a depender da necessidade do paciente, também podem ser recomendadas ${ }^{(5)}$.

A acupuntura nas glândulas salivares, 2 a 20 minutos por semana, durante seis semanas, mostra resultados aceitáveis ${ }^{(\mathbf{1 3})}$.

A laserterapia com comprimento de 685 $\mathrm{nm}$ de forma contínua, potência de $35 \mathrm{~mW}$, aplicada em três pontos em cada parótida, um ponto submandibular direito e outro esquerdo, porém distante de áreas tumorais, traz resultados positivos para pacientes xerostômicos $^{(23)}$.

O deslocamento da glândula submandibular por meio de cirurgia para a área não irradiada submentual é uma medida conservadora eficaz ${ }^{(13)}$.

Os anestésicos tópicos e/ou sistêmicos, os antiinflamatórios e os anti-histamínicos devem ser prescritos após avaliação do oncologista $^{(5)}$.

Em alguns casos, é importante encaminhar o paciente para terapias não farmacológicas no combate à dor. Pode-se recomendar atividades físicas, massoterapia, neuroestimulação elétrica transcutânea, acupuntura, estratégias cognitivo-comportamentais, técnicas de relaxamento, hipnose, terapia em grupo, intervenções psicossociais, que são alternativas terapêuticas que podem trazer melhora na qualidade de vida do paciente oncológico ${ }^{(5)}$.

\section{CÁRIES DE RADIAÇÃo}

As lesões de cáries podem surgir de três semanas a um ano após a radioterapia e localizar-se, geralmente, ao redor das mar- gens cervicais. A saliva não mais desempenha sua função tampão, reguladora do $\mathrm{pH}$ da cavidade bucal, e os componentes orgânicos e inorgânicos dos dentes podem ser alterados tornando-os mais suscetíveis à descalcificação ${ }^{(5)}$.

\section{Tratamento}

É imprescindível orientar o paciente em relação à higiene oral, aconselhando manter-se hidratado e com dieta equilibrada, com menos alimentos açucarados ${ }^{(\mathbf{3 1})}$

As salivas artificiais que contêm flúor e os sialogogos, como a pilocarpina $5 \mathrm{mg}$, via oral, três a quatro vezes ao dia, um dia antes até o término do tratamento, podem ser necessários para restabelecer o equilíbrio da microflora oral ${ }^{(5)}$.

A transferência cirúrgica das glândulas submandibulares para o espaço submental, fora do campo de radiação, preserva a função e previne o desenvolvimento da xerostomia e das cáries ${ }^{(36)}$.

Durante a radioterapia, o exame e a profilaxia com flúor devem ser frequentes, a cada seis a oito semanas. Deve-se fazer as restauração das cáries incipientes após a radioterapia. O acompanhamento deve prosseguir pelo menos 12 meses após a radioterapia, ou mais, se a xerostomia continuar. É recomendável a aplicação de gel de fluoreto de sódio $1 \%$ neutro, uso diário, em moldeira individual, durante 5 a 10 minutos. Não são recomendados os géis acidulados. Também pode-se fazer uso de solução fluoretada $1,0 \%$ a $1,1 \%$, uma vez por semana durante um minuto, ou solução fluoretada $0,05 \%$, duas vezes ao dia, durante um minuto. A escovação com gel de fluoreto estanhoso $0,4 \%$ também é eficaz em cáries de radiação, porém deve-se evitar o uso devido à baixa concentração de flúor e o pH ácido. O verniz fluoretado 22.600 ppm de flúor, duas a três vezes por semana, pode ser uma alternativa, especialmente para o paciente pediátrico ${ }^{(5)}$.

A prescrição de clorexidina gel a $1 \%$ ou a $0,2 \%$, duas vezes ao dia, ou clorexidina em solução $0,12 \%$, por um minuto duas vezes ao dia, também é recomendável para reduzir a flora bacteriana cariogênica ${ }^{(5)}$.

Nestes pacientes, preferencialmente, deve-se optar por restaurações com resinas de cura dual ou ionômero de vidro, e evitar as restaurações com amálgama ${ }^{(5)}$. 


\section{OSTEORRADIONECROSE}

A osteorradionecrose é uma das complicações mais graves da radioterapia, com incidência maior em idosos (10\% a 37\%), e ocorre sete vezes mais na mandíbula do que na maxila, devido à sua alta densidade óssea e menor vascularização. Segundo Ben-David et al. ${ }^{(17)}$, a osteorradionecrose pode ocorrer até dois anos após o término da radioterapia.

De acordo com Thorn et al. ${ }^{(37)}, 74 \%$ dos casos ocorrem nos primeiros três anos após a radioterapia, com maior frequência em pacientes que receberam doses superiores a 60 Gy.

A radiação ionizante torna os canais vasculares estreitos (endarterite obliterante), o que diminui o fluxo sanguíneo, produzindo uma área pouco resistente a trauma e de difícil regeneração, pois há também um decréscimo de osteócitos e osteoblastos viáveis no osso afetado. A doença periodontal ou endodôntica prévia à radiação favorece o acesso dos microrganismos da cavidade bucal às áreas sistêmicas e a necrose óssea ${ }^{(38)}$.

$\mathrm{Na}$ osteorradionecrose, as células ósseas e a vascularização podem ser irreversivelmente injuriadas. Além disso, os riscos de ocorrência da osteorradionecrose continuam indefinidamente após a terapia de irradiação ${ }^{(8)}$. Em osteonecroses crônicas podem ocorrer infecções anaeróbias mistas em que há a prevalências de alguns gêneros de bactérias como Aggregatibacter actinomycetemcomitans, Fusobacterium, Parvimonas e Staphylococcus, provenientes de infecções endodônticas e periodontais $^{(\mathbf{1}, \mathbf{8})}$.

De maneira geral, as exodontias devem ser realizadas no mínimo duas semanas antes do tratamento radioterápico e pelo menos um anos após a conclusão do tratamento. Há um risco maior de osteorradionecrose durante a radioterapia quando o dente envolvido está na direção do feixe de radiação ${ }^{(17)}$.

O risco de osteorradionecrose pós-exodontia é maior quando a localização dos tumores e a exodontia são na mandíbula, em doses superiores a $5.000 \mathrm{cGy}$, especialmente em pacientes com doença periodontal, higiene bucal deficiente e em idosos ${ }^{(2)}$. Nos casos com prognóstico duvidoso ou ruim deve-se fazer uso de cobertura antibiótica desde o dia anterior à cirurgia até o fï da cicatrização ${ }^{(\mathbf{1 5})}$.

Os pacientes que fazem uso de bifosfonados, especialmente ácido zoledrônico, apresentam maior risco de osteorradionecrose $^{(5)}$. Por isso, deve-se planejar com cuidado os procedimentos traumáticos orais, como, por exemplo, as exodontias, raspagens e instalação de próteses. As exodontias após a radioterapia devem ser cuidadosas, com o mínimo descolamento mucoperiosteal e mínima alveoloplastia, sem o preenchimento do alvéolo e com sutura adequada ${ }^{(39)}$. É importante avaliar o risco de infecção odontogênica em pacientes oncológicos. Por isso, é necessário avaliar o hemograma completo do paciente. Se a leucometria for maior do que 3.500 células $/ \mathrm{mm}^{3}$ e as plaquetas estiverem acima de 100.000 células $/ \mathrm{mm}^{3}$, há mais segurança nos procedimentos ambulatoriais. Entretanto, se o paciente apresentar leucopenia ou trombocitopenia, é preciso avaliar a necessidade de intervenção odontológica em ambiente hospitalar e de transfusão plaquetária $^{(5)}$ caso o número de plaquetas seja inferior a 50.000 células $/ \mathrm{mm}^{3}$.

\section{Tratamento}

A oxigenação hiperbárica é uma modalidade de tratamento que melhora a cicatrização da área afetada, promove a angiogênese e reduz os radicais livres. Em alguns casos indicam-se 25 sessões de 90 minu$\operatorname{tos}^{(2)}$.

É recomendável o contato com o oncologista para descontinuar o uso dos bifosfonados nos pacientes que necessitam de exodontias $^{(\mathbf{5})}$.

No tratamento da osteorradionecrose é prescrita a associação antibiótica de amoxicilina, clavulanato e metronidazol durante 10 dias. Além disso, é necessária a irrigação local e diária com clorexidina $0,2 \%$. O desbridamento e a ressecção completa de área necrosada e reconstrução com nova antibioticoterapia devem ser avaliados cuidadosamente $^{(\mathbf{5 , 1 7})}$.

\section{DOENÇA PERIODONTAL}

O periodonto, assim como todos os outros tecidos, também é sensível aos efeitos da radiação em altas doses ${ }^{(\mathbf{4 0 )}}$. Os vasos sanguíneos não apenas do periodonto, como também do periósteo, são afetados. Radiograficamente, observam-se modificações no alvéolo, com a ampliação do espaço do ligamento periodontal e destruição do osso trabecular. Estas alterações aumentam o risco de doença periodontal, pois há uma redução na capacidade de reparo e remodelação óssea ${ }^{(4)}$. Além disso, com a xerostomia e a supressão imunológica ocorre uma modificação da flora bacteriana oral em geral, com aumento de bactérias Gram negativas (Streptococcus mutans, Lactobacilos e Actinomyces naeslundi, $P$. gingivalis $)^{(\mathbf{8})}$.

Em pacientes com plaquetopenia (plaquetas abaixo de $30.000 / \mathrm{mm}^{3}$ ) não é possível realizar uma escovação efetiva nem o uso de fio dental, por causa do risco de hemorragia. Para esses pacientes, recomenda-se o uso de cotonetes, suabes ou gaze com soro fisiológico e bochechos com soluções antissépticas na remoção da placa bacteriana.

A avaliação dentária e periodontal como conduta pré-radioterápica é essencial no prognóstico do paciente. A literatura é controversa no que concerne ao período exato para as exodontias. Em dentes com bolsa periodontal (maior que $4 \mathrm{~mm}$ ) e/ou mobilidade grau $\mathrm{I}^{(\mathbf{1 6})}$, ou ainda em bolsas maiores que $6 \mathrm{~mm}$, com envolvimento de furca, com dente próximo ao local em que será aplicada a radioterapia, as altas doses, a higiene oral ruim e a pouca cooperação do paciente $^{(\mathbf{1 4})}$ são fatores indicativos de exodontia antes da radioterapia, para evitar osteorradionecrose.

\section{Tratamento}

A orientação em higiene oral antes e após a radioterapia é imprescindível, especialmente em pacientes que apresentam a doença periodontal antes do tratamento radioterápico. Os procedimentos de raspagem e alisamento radicular devem ser instituídos preferencialmente antes ou após a radioterapia $^{(11)}$.

A remoção de fatores de acúmulo de placa, como próteses mal adaptadas, excesso de restaurações, restos radiculares, dentes fraturados, lesões de cárie cavitadas, deve ser realizada antes da radioterapia, bem como as exodontias de dentes com maior comprometimento periodontal. O 
tratamento reconstrutivo da doença periodontal com a utilização de enxertos ósseos pode ser realizado antes da radioterapia ${ }^{(38)}$, porém deve ser planejado cuidadosamente para evitar osteorradionecrose.

A laserterapia é uma alternativa que complementa o tratamento e preferencialmente deve ser aplicado antes da radioterapia $^{(41)}$.

\section{TRISMO}

O trismo é uma sequela que aparece, geralmente, entre a terceira e a sexta semana após o término do tratamento radioterápico e que limita a abertura bucal, dificulta a alimentação, a fonação, o exame da cavidade oral, o tratamento dentário, a higienização oral, e causa intenso descon-

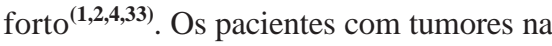
faringe, em áreas retromolares e regiões posteriores do palato, são os mais afetados. Ou ainda, quando os músculos mastigatórios fazem parte do campo de radiação, há como consequências edema, destruição celular e fibrose muscular ${ }^{(\mathbf{4 , 6})}$.

\section{Tratamento}

A fisioterapia com exercícios dos músculos mastigatórios envolvidos, com o uso de abridores dinâmicos de boca para alongá-los, é eficaz para aumentar a abertura bucal $^{(27)}$.

Os antiinflamatórios não esteroidais e relaxantes musculares (ciclobenzaprina 10 mg, de 8/8 horas durante sete dias) são recomendáveis para reduzir os sintomas de dor. A pentoxifilina é eficaz nos casos de trismo, pois tem ação imunomodulatória, que regula certas citocinas mediadoras de reações fibrogênicas depois da radiação ${ }^{(27)}$.

\section{ALTERAÇÕES DE DESENVOLVIMENTO}

Dentre as alterações mais comuns em pacientes pediátricos destacam-se as anormalidades do desenvolvimento esquelético craniofacial (micrognatia mandibular, ou retrognatismo maxilar), alterações na odontogênese, hipoplasia de esmalte, parada de desenvolvimento do órgão dentário, agenesias, microdontias e alterações na rizogênese, tais como interrupção, afilamento e alargamento da câmara pulpar ${ }^{(\mathbf{1 6})}$.

\section{CONCLUSÕES}

Um protocolo que minimize as sequelas da radioterapia deve ser previamente instituído e monitorado antes, durante e após a finalização do tratamento. A conduta clínica multidisciplinar integral permite prevenir, diagnosticar e controlar os efeitos colaterais da radioterapia. Os aspectos psicológicos são relevantes e a autoestima do paciente pode favorecer na adesão ao tratamento proposto, no cuidado pessoal e com sua dentição.

\section{REFERÊNCIAS}

1. Langendijk JA. New developments in radiotherapy of head and neck cancer: higher precision with less patient discomfort? Radiother Oncol. 2007;85:1-6

2. Salazar M, Victorino FR, Paranhos LR, et al. Efeitos e tratamento da radioterapia de cabeça e pescoço de interesse ao cirurgião dentista: revisão da literatura. Odonto (São Bernardo do Campo). 2008;16:62-8.

3. Huber MA, Terezhalmy GT. The head and neck radiation oncology patient. Quintessence Int. 2003;34:693-717.

4. Vissink A, Jansma J, Spijkervet FK, et al. Oral sequelae of head and neck radiotherapy. Crit Rev Oral Biol Med. 2003;14:199-212.

5. Rankin KV, Jones DL, Redding SW. Oral health in cancer therapy. A guide for health care professionals. 3rd ed. [Internet]. 2008. [cited 2010 Dec 14]. Available from: http://www.doep.org/images/ OHCT_III_FINAL.pdf

6. Silverman S Jr. Oral cancer: complications of therapy. Oral Surg Oral Med Oral Pathol Oral Radiol Endod. 1999;88:122-6.

7. Dib LL, Gonçalves RCC, Kowalski LP, et al. Abordagem multidisciplinar das complicações orais da radioterapia. Rev Assoc Paul Cir Dent. 2000;54:391-6.

8. Geraldes AM, Jardim Júnior EG, Campos MJA, et al. Ocorrência de Porphyromonas gingivalis na microbiota bucal de pacientes submetidos à radioterapia para tratamento de lesões malignas de cabeça e pescoço. Rev Odontol Araçatuba. 2009; 30(Supl 1):41.

9. Niehoff P, Springer IN, Açil Y, et al. HDR brachytherapy irradiation of the jaw - as a new experimental model of radiogenic bone damage. J Craniomaxillofac Surg. 2008;36:203-9.

10. Epstein JB, Robertson M, Emerton S, et al. Quality of life and oral function in patients treated with radiation therapy for head and neck cancer. Head Neck. 2001;23:389-98.

11. Faloni APS, Lorenzon AP, Margonar R, et al. Importância dos procedimentos periodontais prévios à radioterapia em região de cabeça e pescoço. Rev Int Periodontia Clin. 2005;2:93-9.

12. Wright WE, Haller JM, Harlow SA, et al. An oral disease prevention program for patients receiving radiation and chemotherapy. J Am Dent Assoc. 1985;110:43-7.

13. Shiboski CH, Hodgson TA, Ship JA, et al. Management of salivary hypofunction during and af- ter radiotherapy. Oral Surg Oral Med Oral Pathol Oral Radiol Endod. 2007;103 Suppl:S66.e1-19.

14. Bruins HH, Jolly DE, Koole R. Preradiation dental extraction decisions in patients with head and neck cancer. Oral Surg Oral Med Oral Pathol Oral Radiol Endod. 1999;88:406-12.

15. Santos MG, Silva LCF, Lins CA, et al. Fatores de risco em radioterapia de cabeça e pescoço. RGO - Rev Gaúcha Odontol (Porto Alegre). 2010;58 191-6.

16. Albuquerque RA, Morais VLL, Sobral APV. Protocolo de atendimento odontológico a pacientes oncológicos pediátricos - revisão da literatura. Rev Odontol UNESP. 2007;36:275-80.

17. Ben-David MA, Diamante M, Radawski JD, et al. Lack of osteoradionecrosis of the mandible after intensity-modulated radiotherapy for head and neck cancer: likely contributions of both dental care and improved dose distributions. Int J Radiat Oncol Biol Phys. 2007;68:396-402.

18. Neville BW, Damm DD, Allen CM, et al. Patologia oral e maxilofacial. $2^{\mathrm{a}}$ ed. Rio de Janeiro, RJ: Guanabara Koogan; 2004.

19. Karbach J, Callaway A, Kwon YD, et al. Comparison of five parameters as risk factors for perimucositis. Int J Oral Maxillofac Implants. 2009; 24:491-6.

20. Raber-Durlacher JE, Elad S, Barasch A. Oral mucositis. Oral Oncol. 2010;46:452-6.

21. Bensadoun RJ, Franquin JC, Ciais G, et al. Lowenergy $\mathrm{He} / \mathrm{Ne}$ laser in the prevention of radiationinduced mucositis. A multicenter phase III randomized study in patients with head and neck cancer. Support Care Cancer. 1999;7:244-52.

22. Kelner N, Castro JFL. Laser de baixa intensidade no tratamento da mucosite oral induzida pela radioterapia: relato de casos clínicos. Rev Bras Cancerol. 2007;53:29-33.

23. Campos L, Simões A, Sá PHRN, et al. Improvement in quality of life of an oncological patien by laser phototherapy. Photomed Laser Surg. 2009;27:371-4.

24. Simões A, de Campos L, de Souza DN, et al. Laser phototherapy as topical prophylaxis against radiation-induced xerostomia. Photomed Laser Surg. 2010;28:357-63.

25. Lima AG, Antequera R, Peres MP, et al. Efficacy of low-level laser therapy and aluminum hydroxide in patients with chemotherapy and radiotherapy-induced oral mucositis. Braz Dent J. 2010;21:186-92.

26. Gouvêa de Lima A, Villar RC, de Castro G Jr, et al. Oral mucositis prevention by low-level laser therapy in head-and-neck cancer patients undergoing concurrent chemoradiotherapy: a phase III randomized study. Int J Radiat Oncol Biol Phys. 2010 Dec 14. [Epub ahead of print].

27. Andrade ED. Terapêutica medicamentosa em odontologia. São Paulo, SP: Artes Médicas; 1998.

28. Antonadou D, Pepelassi M, Synodinou M, et al. Prophylactic use of amifostine to prevent radiochemotherapy-induced mucositis and xerostomia in head-and-neck cancer. Int J Radiat Oncol Biol Phys. 2002;52:739-47.

29. Rosenthal C, Karthaus M. Current approaches in prevention and therapy of chemo- and radiotherapy-induced oral mucositis. Wien Med Wochenschr. 2001;151:53-65.

30. Noé JE. L-glutamine use in the treatment and 
prevention of mucositis and cachexia: a naturopathic perspective. Integr Cancer Ther. 2009;8: 409-15.

31. van Bokhorst-de van der Schueren MA. Nutritional support strategies for malnourished cance patients. Eur J Oncol Nurs. 2005;9 Suppl 2:S74 83.

32. Brasil. Ministério da Saúde. Instituto Nacional de Câncer. Consenso nacional de nutrição oncológica. [Internet]. 2009. [acessado em 6 de setembro de 2011]. Disponível em: http://www.inca. gov.br/inca/Arquivos/publicacoes/ Consenso_Nutricao_internet.pdf

33. Harrison JS, Dale RA, Haveman CW, et al. Oral complications in radiation therapy. Gen Dent. 2003;51:552-60.
34. Moss RW. Should patients undergoing chemotherapy and radiotherapy be prescribed antioxidants? Integr Cancer Ther. 2006;5:63-82.

35. Lerman MA, Laudenbach J, Marty FM, et al. Management of oral infections in cancer patients. Dent Clin North Am. 2008;52:129-53.

36. Jha N, Seikaly H, McGaw T, et al. Submandibular salivary gland transfer prevents radiation-induced xerostomia. Int J Radiat Oncol Biol Phys. 2000;46:7-11.

37. Thorn JJ, Hansen HS, Specht L, et al. Osteoradionecrosis of the jaws: clinical characteristics and relation to the field of irradiation. J. Oral Maxillofac. Surg. 2000;58:1088-93.

38. Jegoux F, Malard O, Goyenvalle E, et al. Radiation effects on bone healing and reconstruction: interpretation of the literature. Oral Surg Oral Med Oral Pathol Oral Radiol Endod. 2010;109: 173-84.

39. Agbaje JO, Jacobs R, Michiels K, et al. Bone healing after dental extractions in irradiated patients: a pilot study on a novel technique for volume assessment of healing tooth sockets. Clin Oral Investig. 2009;13:257-61.

40. Epstein JB, Lunn R, Le N, et al. Periodontal attachment loss in patients after head and neck radiation therapy. Oral Surg Oral Med Oral Pathol Oral Radiol Endod.1998;86:673-7.

41. Angelov N, Pesevska S, Nakova M, et al. Periodontal treatment with a low-level diode laser: clinical findings. Gen Dent. 2009;57:510-3. 